\title{
ASSESSMENT AND PERFORMANCE-BASED DESIGN OF THE STRENGTHENING OF EXISTING STRUCTURES FOLLOWING THE 2015 NEPAL EARTHQUAKES
}

\author{
TIMOTHY SMALL \\ Arcadis Asia Pacific, Australia
}

\begin{abstract}
During the 2015 Nepal earthquakes, buildings throughout the country experienced substantial damage resulting in significant casualties and economic loss. In the aftermath of this event, buildings throughout the country underwent seismic assessment to determine the extent of damage and to establish whether they would achieve their required performance level in the event of a subsequent earthquake. In mid2016, an assessment was conducted of four Australian-owned buildings in central Kathmandu. The American Society of Civil Engineers building code "Seismic Evaluation and Retrofit of Existing Buildings" (ASCE-41) was used as a general framework for the identification of structural deficiencies and subsequent analysis. Numerous international standards were utilised to derive analysis inputs where the requirements of ASCE-41 could not be met. A performance-based design approach was adopted to design strengthening measures which fulfilled the performance objectives of both the client and relevant building codes and were sensitive to local expertise, materials and abilities. In this paper, we report on the post-earthquake condition of the four assessed buildings, typical structural deficiencies that were identified, the way by which the performance-based seismic analysis was conducted, and how the limitations of the relevant design codes were resolved.

Keywords: seismic retrofitting, masonry structures, Nepal national building code, performance-based design, seismic assessment, ASCE-41.
\end{abstract}

\section{INTRODUCTION}

The Nepal National Building Code (NBC) was first published in 1994. Prior to this, there were no building codes which mandated minimum building structural requirements in Nepal [1]. This meant that the vast majority of buildings in the country were not designed to resist seismic loading at the time of the 2015 earthquakes [2], resulting in substantial damage to buildings and loss of life. After this event, many buildings in Nepal underwent assessment to determine their structural integrity.

After any significant seismic event, it is essential that there are systematic, detailed and context-appropriate building codes for use by engineers to ensure that buildings are accurately and efficiently assessed to ensure that they continue to fulfil their function. Three codes which partly address seismic design for the types of buildings which are the subject of this paper are NBC-105 "Seismic Design of Buildings in Nepal", NBC-203 "Guidelines for Earthquake Resistant Building Construction: Low Strength Masonry", and RCC Structures - "Seismic Retrofitting Guidelines of Buildings in Nepal". NBC-105 is the Nepalese code for seismic design of new buildings, NBC-203 is a largely qualitative set of principles for earthquake-resistant construction and RCC Structures does not offer the level of detail that is often required in complex assessments, particularly regarding material strengths. Even if RCC Structures was adopted for the analysis, there would still need to be significant reliance on other international building codes for quantitative guidance on various values.

Ideally, a code should be applied in its entirety to a building without the need to look to other codes to justify parts of the analysis. In this case study, it was found that this was not possible, and instead, parts of various international codes had to be used in conjunction with good engineering judgement to achieve a satisfactory outcome. 
Four buildings located in central Kathmandu were assessed by Arcadis in the wake of the 2015 earthquakes. Prior to 2015, an assessment of the buildings had been conducted by a local engineering consultancy using the requirements of NBC-105. However, in the wake of the earthquakes, the building owners decided that a more thorough assessment should be conducted using the detailed and systematic procedures of ASCE-41. It was hoped that in using a more accurate higher-order analysis, the resulting strengthening would be less intrusive and costly. This formed Arcadis' Statement of Requirements (SOR) for the project.

Structural deficiencies were identified using three methods: visual/Tier 1 inspection (Section 2.2) survey testing results (Section 2.3) and computer analysis (Section 5). Strengthening measures were then designed to rectify these deficiencies (Section 6). This paper may be used by engineers when deciding on the most appropriate approach for the analysis and strengthening of existing structures in developing countries.

\subsection{Building description}

\section{BUILDING DESCRIPTION}

The four assessed buildings had similar structural systems - reinforced concrete slabs and beams supported predominantly by load-bearing unreinforced masonry walls or (in some locations) supported by reinforced concrete or unreinforced masonry columns. Many of the upper-level masonry walls were supported on reinforced concrete beams and did not continue to the foundations. No evidence of piling was apparent for any of the buildings. Three of the buildings had car ports at the front of the buildings which acted largely as stand-alone structures. Fig. 1 shows typical structural framing of the buildings.

The buildings were originally built approximately 25 to 30 years ago, prior to the publication of NBC-105. This made it unlikely that they complied with the current local requirements for seismic design, nor to international standards. After the original construction, two of the buildings had substantial additions to increase the footprint area (i.e. not additional storeys).

There are no structural drawings from the original construction of the building; the only drawings were made during a site survey in 2014. However, these drawings were not complete or detailed enough for our requirements.

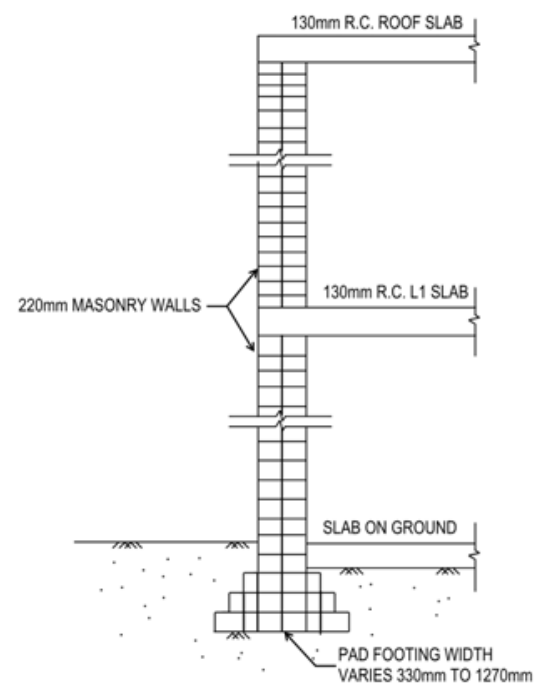

Figure 1: Typical structural framing. 


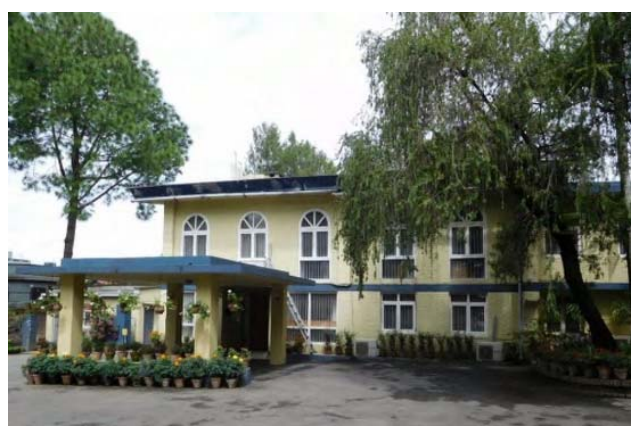

Figure 2: Building 1.

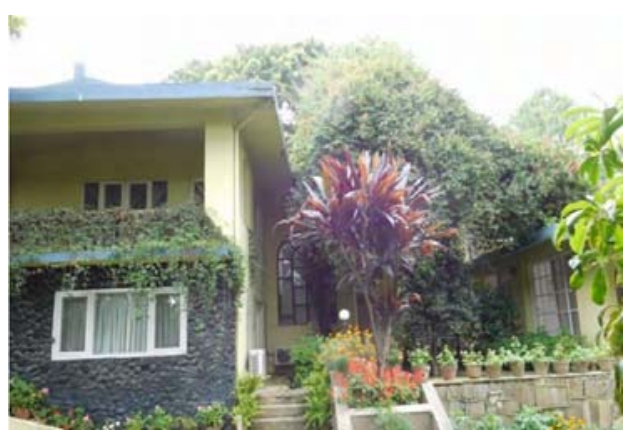

Figure 4: Building 3.

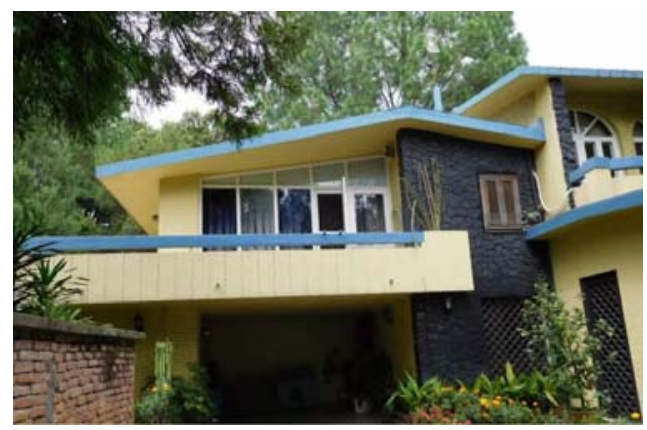

Figure 3: Building 2.

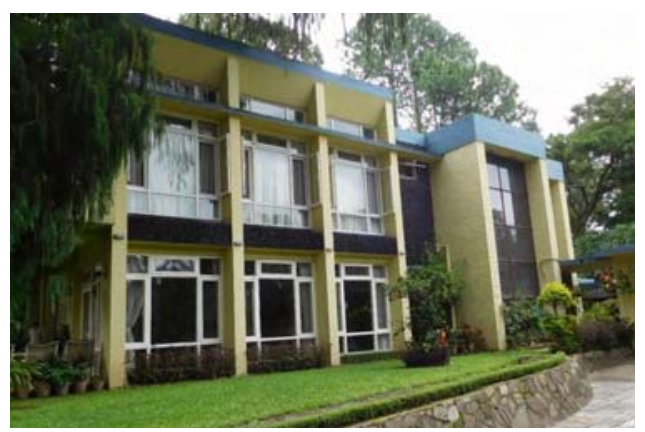

Figure 5: Building 4.

\subsection{Tier 1 deficiencies}

According to ASCE-41, there are three tiers of assessment which may be used to conduct a seismic evaluation of a building. The Tier 1 assessment includes checklists to identify highlevel deficiencies. An engineer from Arcadis travelled to Kathmandu in late-2015 and conducted this assessment. From this assessment, non-conformities were identified. Some of these were rectified by a construction team immediately after the initial site visit. However, many of the deficiencies required a more detailed form of assessment (Tier 2 assessment). Common deficiencies which were identified during the Tier 1 assessment included:

1. Vertical irregularities; in some locations, shear walls did not continue to foundations.

2. Soft storeys.

3. Potential for torsion; Building 2 had very few shear walls in the northern and central areas of the ground floor, building 3 was built in a U-shape, with very little stiffness in the North-South direction in one of the wings, and Building 4 had many split levels with a high number of masonry shear walls to the South but very few in the North, which generally reduced building robustness.

4. Proximity of windows and other large openings to building corners.

5. The connection of masonry walls to concrete slabs were unknown.

6. In some of the buildings, the height-to-width ratio was too great, resulting in the potential for overturning. 
According to ASCE-41, these points mandated an in-depth assessment. Arcadis decided that it would be feasible to conduct a detailed computer modelling exercise for the four buildings. The Tier 2 assessment and subsequent full building analysis as per ASCE-41 Chapter 7 was the aim of the second site visit in mid-2016.

\subsection{Building damage}

The effects of the earthquake loading on the buildings were also observed during this assessment. There was generally less damage to the buildings from the earthquake than may have been expected. The damage which was observed was typically:

- Minor cracking in arches or at the top of columns, and

- Cracks of approximately $5 \mathrm{~mm}$ width at the tops of columns supporting concrete carport roofs.

Figs 6 and 7 show typical damage that was observed.

The observations, combined with our analysis, confirmed that under seismic actions, hinges were forming at the top and bottom of vertical elements. Fig. 8 shows a diagram of the effect of earthquake actions on the structures.

\subsection{Site survey}

The team from Arcadis was on site for one week in May 2016 to collect additional information to allow for a Tier 2 assessment. During that time, Arcadis observed the existing condition of the buildings and understood the layout of the buildings to assist with modelling and calculations.

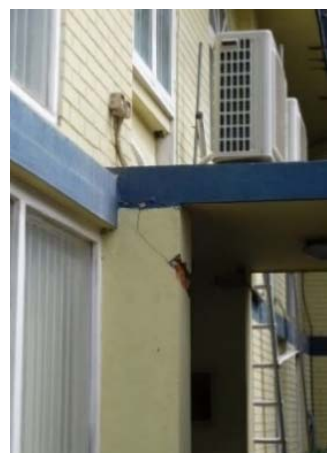

Figure 6: Crack in wall.

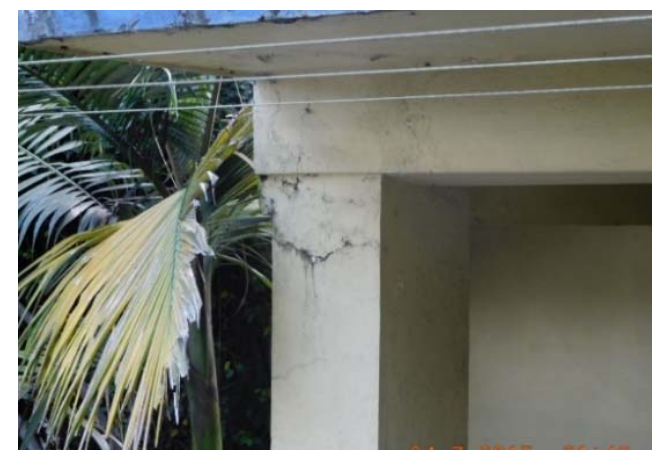

Figure 7: Crack in column.

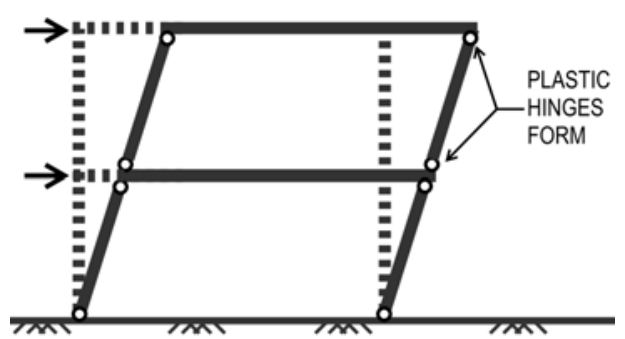

Figure 8: Behaviour of inspected structures under seismic loading. 
A local consultancy had been engaged to collect in-depth information about the buildings. The main points which the local survey team were tasked with identifying were:

- Materials of structural elements: most of the elements within the buildings had been rendered, making it very difficult to identify the original construction material. The survey team was therefore asked to do opening-up works to identify construction materials.

- Reinforcement detailing: design for seismic loading relies heavily on connection detailing, the area where retrofits usually lack design data.

- Foundation sizes: although the typical shape of foundations was known from previous investigations, sizes differed between the buildings. We therefore needed pits to be dug around the buildings to confirm these sizes.

- Building layout: the survey team was asked to confirm the layout of all the buildings, including plan set-out and heights of major building steps.

- Material strengths: unfortunately, the material capacities could not be tested as per ASCE-41 requirements (refer section 4.1).

Where conclusive data regarding the structures could not be obtained, we could rely on the considerable experience of the local survey team to make reasonable assumptions about the structure where required.

\section{ANALYSIS APPROACH}

The main tasks that were performed as part of this assessment are shown in Fig. 9.

\subsection{Performance criteria}

The ASCE-41 has four Basic Performance Objectives for Existing Buildings (BPOE) relating to the level of usage that is required after an earthquake event; "Life Safety", "Collapse Prevention", "Damage Control" and "Immediate Occupancy".

In the event of a future earthquake, building 1 was to be used to assist with humanitarian response, meaning that "Immediate Occupancy" (I.O.) was the most appropriate performance level. As defined by ASCE-41, a building defined as I.O. is one where the building is essentially completely functional after the earthquake; "the post-earthquake damage state in which only very limited structural damage has occurred." [3] The other three buildings were designated the less stringent "Life Safety" (L.S.), meaning that the "structure has damaged components but retains a margin against the onset of partial or total collapse." [3] This was acceptable as these buildings would not be used in a post-disaster function.

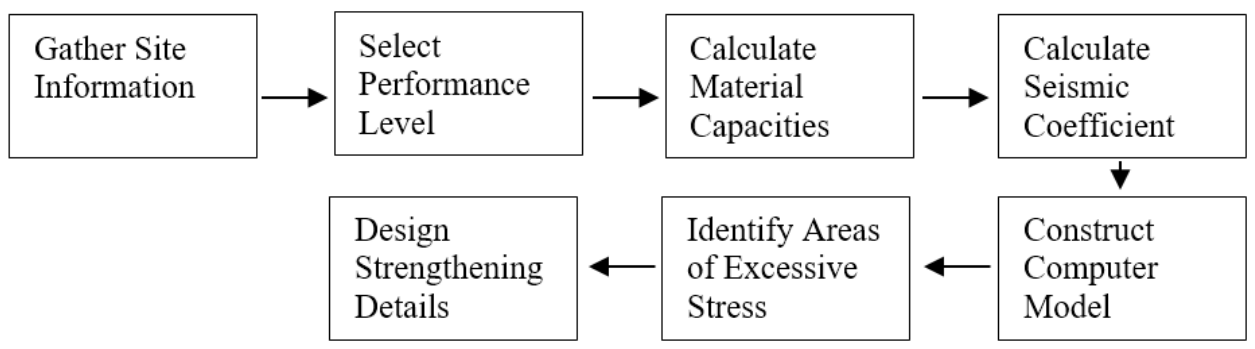

Figure 9: Main tasks completed in the analysis. 
For loads to be used in this analysis, ASCE-41 specifies a Basic Safety Earthquake-1 for Existing Buildings (BSE-1E). This is defined as a seismic hazard with a $20 \%$ probability of exceedance in 50 years. Due to designation of Building 1 as I.O., there were additional requirements for the assessment and modelling, including:

1. The importance factor for the building, (' $\mathrm{I}$ ' in NBC-105, ' $\mathrm{I}_{\mathrm{e}}$ ' in ASCE-41/7) increases from 1.0 for a L.S. - designated building to 1.5 for I.O.

2. It is not permitted to consider any contribution of strength due to unreinforced masonry in Tiers 1 and 2 analyses (ASCE-41 Table 3-2). As it wasn't feasible to use a Tier 3 analysis, this presented difficulties as we would therefore need to reinforce every wall which we wished to consider in the resistance of seismic loading.

3. It is recommended that pile foundations are used for buildings in this category.

\section{DESIGN INPUTS}

Being an internationally accepted standard, ASCE-41 provided the general framework for our analysis. However, other codes were referenced to obtain necessary inputs where requirements of ASCE-41 could not be met due to local constraints. For critical values, such as material strengths and seismic loads, multiple codes were used to achieve a high level of accuracy.

Table 1 gives a summary of the inputs that were used, and the applicable standard.

Table 1: Design, analysis inputs.

\begin{tabular}{|l|l|}
\hline Element & Referenced Standard \\
\hline Masonry Characteristic & TMS-602-13 \\
Compressive Capacity, f' $m$ & TMS-402 \\
& ASCE-41 \\
& AS3700 \\
& Kaushik, Rai and Jain Research Article [4] \\
& IS1905 \\
\hline Masonry Modulus of Rupture, $\mathrm{f}_{\mathrm{r}}$ & TMS-402 \\
& TMS-602-13 \\
& ASCE-41 \\
& IS1905 \\
\hline Seismic Loading & ASCE-41 \\
& ASCE-7 \\
& NBC-105 \\
\hline Concrete Slab Capacities & AS3600 \\
& ACI-31 \\
\hline General Analysis Approach & ASCE-41 \\
& AS1170.4 \\
\hline
\end{tabular}

Note: TMS-602 is "Specification for Masonry Structures" (USA), TMS-402 is "Building Code Requirements for Masonry Structures" (USA), AS3600 is "Concrete Structures" (Australia), AS3700 is "Masonry Structures" (Australia), AS117.04 is "Structural Design Actions - Earthquake" (Australia), IS1905 is "Code of Practice for Structural Use of Unreinforced Masonry" (India) and ACI-31 is "Building Code Requirements for Reinforced Concrete" (USA). 


\subsection{Material testing}

Part of the brief to the local survey company was to conduct destructive material testing of bricks and mortar in accordance with ASCE-41. However, given the local building practices, it was not possible to fulfil these requirements (as found in ASCE-41 section 11.2.3.3), such as the extraction and testing of mortar prisms or flatjack testing.

The two parameters from which masonry strength can be calculated in accordance with TMS-402 are compressive strength, $\mathrm{f}_{\mathrm{m}}$, and modulus of rupture, $\mathrm{f}_{\mathrm{r}}$.

\subsubsection{Calculation of $\mathrm{f}^{\prime} \mathrm{m}$}

Three procedures were used in the calculation of $\mathrm{f}^{\prime} \mathrm{m}$ and compared to ensure accuracy:

1. Using AS3700 and TMS 602-13

a. Compressive strength testing was conducted for 3 brick samples

b. The characteristic brick strength, $\mathrm{f}^{\prime}$ uc, was determined in accordance with the AS3700-2011 Appendix B

c. Masonry compressive strength, $\mathrm{f}_{\mathrm{m}}$, was extrapolated from American masonry compressive strength data for $\mathrm{N}$ class mortar (as per TMS 60213: 1.4) and multiplied by a reduction factor to account for the mortar, which is likely weaker than American N class mortar

2. Using AS3700 alone:

a. Classifying mortar as the weakest class, M2

b. Characteristic unconfined compressive strength, $\mathrm{f}^{\prime}$ uc, obtained in accordance with step 1 . b. of the above procedure

c. Characteristic compressive strength of masonry, $\mathrm{f}^{\prime} \mathrm{mb}$, (being equal to masonry compressive strength, $\mathrm{f}_{\mathrm{m}}$ ) determined using linear interpolated from values in AS3700-2011: Table 3.1

3. Using an Indian research article authored by Kaushik, Rai and Jain [4]:

a. Mean compressive strength, $\mathrm{f}_{\mathrm{b}}$, was obtained from test results

b. A trendline was developed to determine the relationship between the $f_{b}$ and $\mathrm{f}_{\mathrm{m}}$ values from the research article

c. Masonry compressive strength, $\mathrm{f}^{\prime}$, was determined by plotting tested $\mathrm{f}_{\mathrm{b}}$ on the trendline

\subsubsection{Calculation of $\mathrm{f}_{\mathrm{r}}$}

Mortar testing was not available for this project, therefore the modulus of rupture, $\mathrm{f}_{\mathrm{r}}$, was obtained from TMS-402: T9.1.9.2 for $\mathrm{N}$ class mortar and further multiplying by a reduction factor to account for weaker mortar. $\mathrm{N}$ class mortar as per TMS-402 is approximately $5 \mathrm{MPa}$, with the in-situ mortar taken as 3-5MPa, as per IS1905.

\subsubsection{Wall capacities}

The reduction factor applied to both $\mathrm{f}_{\mathrm{m}}$ and $\mathrm{f}_{\mathrm{r}}$ has been taken as the minimum expected mortar strength divided by the strength of $\mathrm{N}$ type mortar, $3 / 5=0.6$. Masonry capacities were calculated using $\mathrm{f}_{\mathrm{m}}$ and $\mathrm{f}_{\mathrm{b}}$ in accordance with TMS-402 as directed by ASCE-41-13: 11.3, taking the strength reduction factor, $\varphi$, as 1.0. Obtaining stress limits in this way and comparing to calculated stresses was most appropriate for the finite element analysis undertaken. The following masonry strengths were calculated:

\subsection{Seismic coefficient}

Two standards were used for the calculation of seismic coefficient; the ASCE-41 (which references ASCE-7) or NBC-105. By using United States Geological Survey maps, local seismic loading values were identified (such as spectral response acceleration parameters). 
Table 2: Calculated masonry capacities.

\begin{tabular}{|c|c|c|}
\hline PARAMETER & Magnitude & Source \\
\hline Out-of-plane shear & $0.38 \mathrm{MPa}$ & TMS 402-13: 9.1.7 \\
\hline Bearing & $3.10 \mathrm{MPa}$ & TMS 402-13: 9.1 .8 \\
\hline $\begin{array}{ll}\text { Compressive } & \text { from } \\
\text { Flexure } & \\
\end{array}$ & $3.10 \mathrm{MPa}$ & TMS 402-13: 9.2.4 \\
\hline Tension from flexure & $0.41 \mathrm{MPa}$ & TMS 402-13: 9.2.4 \\
\hline $\begin{array}{l}\text { Axial Compression } 225 \\
\text { Wall }\end{array}$ & $2.48-0.03 * h^{2} \mathrm{MPa}$ & TMS 402-13: 9.2.4 \\
\hline $\begin{array}{l}\text { Axial Compression } 350 \\
\text { Wall }\end{array}$ & $2.48-0.01 * h^{2} \mathrm{MPa}$ & TMS 402-13: 9.2.4 \\
\hline In-Plane Shear & $0.62 \mathrm{MPa}$ & TMS 402-13: 9.2.6 \\
\hline Direct Tension & $0 \mathrm{MPa}$ & TMS 402-13: 9.2.5 \\
\hline
\end{tabular}

where $\mathrm{h}=$ height of wall

Table 3: Static earthquake loads.

\begin{tabular}{|l|l|l|l|}
\hline \multirow{2}{*}{} & \multicolumn{3}{|c|}{ EQ Lateral Force (\%g) } \\
\cline { 2 - 4 } & Kathmandu Buildings & If Buildings were in California \\
\cline { 2 - 4 } & ASCE-7 & NBC & ASCE-7 \\
\hline L.S. & 34 & 32 & 27 \\
\hline I.O. & 52 & 48 & 40 \\
\hline
\end{tabular}

These values were then compared to an equivalent value from the Nepal National Building Code (NBC-105) to ensure accuracy. The value calculated using NBC-105 was within $8 \%$ of the value from the ASCE-41 and the internally referenced ASCE-7. Table 3 shows the static earthquake loads on the buildings, as derived from the two standards. For reference, this is compared to the worst-case earthquake load acting on the buildings if they had been in California, USA.

\subsection{Piling}

It is recommended in ASCE-41 that piling is used to prevent uplift and sliding in I.O. buildings, such as Building 1. No evidence of existing piled foundations was found. Furthermore, our analysis showed there was significant potential uplift at the foundations in some locations. Considering local building expertise, it was unlikely that it would be possible to construct piles with sufficient capacity so close to the buildings, and to sufficiently tie in the piles to the existing structure. Footing enlargements were therefore designed to increase footing mass and friction with the soil.

\section{BUILDING ANALYSIS}

\subsection{Computer modelling}

The building analysis and design of strengthening was conducted in the following way:

1. Each building was modelled in the analysis program ETABS, modelling all major structural elements. 
2. Loads derived from the applicable codes as described above were entered into the analysis model.

3. The distribution of forces to structural elements was identified from the model and compared to approximate values derived from hand calculations.

4. Wall stresses (tension, compression or shear) which exceeded the maximum allowable values described above were identified.

5. Concrete beams were checked using RAPT analysis software with earthquake loads acting in combination with factored gravity loads.

6. Strengthening details were designed to reinforce areas of excessive stress.

7. Foundations were checked for compression and uplift. Footings were enlarged where required.

The following points are noted regarding the modelling procedure:

- For I.O. buildings, it is not permitted to consider the strength of unreinforced masonry walls when using Tier 1 or Tier 2 analysis. Two separate building models were therefore built for this structure; one model with all existing walls to determine the gravity loads on the walls, and the other with walls to be strengthened only, to calculate the distribution of earthquake forces on the walls. By comparing these two models, maximum loads in the selected walls during an earthquake were determined.

- The lateral effect of retained soil on the structures was calculated by hand and compared to the earthquake loading. It was typically found that the effect of the soil was comparatively small and would therefore not significantly influence the behaviour of the building.

\section{RECTIFICATION OPTIONS FOR DEFICIENCIES}

Due to local expertise in the use of advanced engineering methods and materials was limited, construction was restricted to concrete, grout and steel. It was also decided to make details as uncomplicated as possible, making it easier to answer questions about the strengthening remotely (from Australia), and to ensure that the general structural intent was locally achievable. Finally, it was important to ensure that the repair upgrades were as practical and unobtrusive as possible, and not adversely impact on the building function.

Four main types of strengthening were designed in response to key deficiencies identified: wall strengthening, foundation enlargement, wall extension and stitch plates.

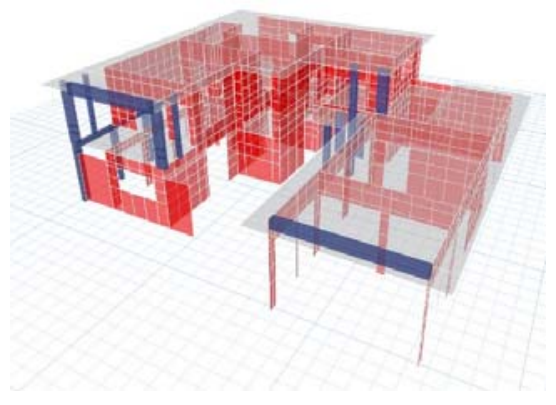

Figure 10: Building 3 analysis model.

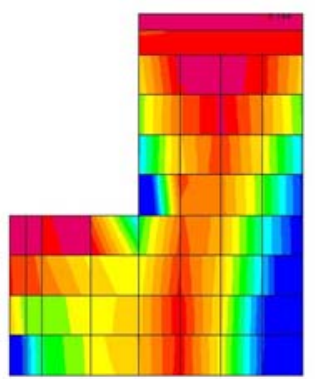

Figure 11: Maximum wall stresses under seismic and gravity loads. 


\subsection{Wall strengthening}

The site survey confirmed that reinforcement did not pass from slabs into walls, meaning that wall to slab connections frequently failed in tension. In addition, the masonry walls themselves also failed in tension in many places. A practical solution was to design steel reinforcing on the outside of the walls as a reinforced jacket and anchor in the slab above and below. This method was used extensively in Building 1 to reinforce all walls that were to be considered in the lateral analysis. Fig. 12 shows typical wall strengthening details.

\subsection{Foundation enlargement}

One of the most onerous parts of the strengthening process was increasing footing sizes. It was calculated that uplift loads of around $200 \mathrm{kN} / \mathrm{m}$ might be experienced in some locations. Reinforcement from wall jacketing was anchored into the footings, and dowels were installed into the masonry walls. We decided against excavating under foundations as this would necessitate underpinning of the structure which would be complicated and would introduce risks both in terms of the quality of the finished product and safety of workers. Fig. 13 shows a typical footing strengthening detail.

\subsection{Wall extension}

To reduce peak tensile and compressive loads in walls, several walls were lengthened by installing reinforced concrete walls tied into the existing masonry walls and installing foundations under, decreasing the amount of wall jacketing and extent of foundation strengthening. These wall extensions could be located on external walls, decreasing the amount of construction within the buildings themselves, leading to a less complicated and costly construction process. Fig. 14 shows a typical wall extension detail. Note the vertical stitching plate which was designed to transmit shear loads from existing masonry wall into the new concrete wall.
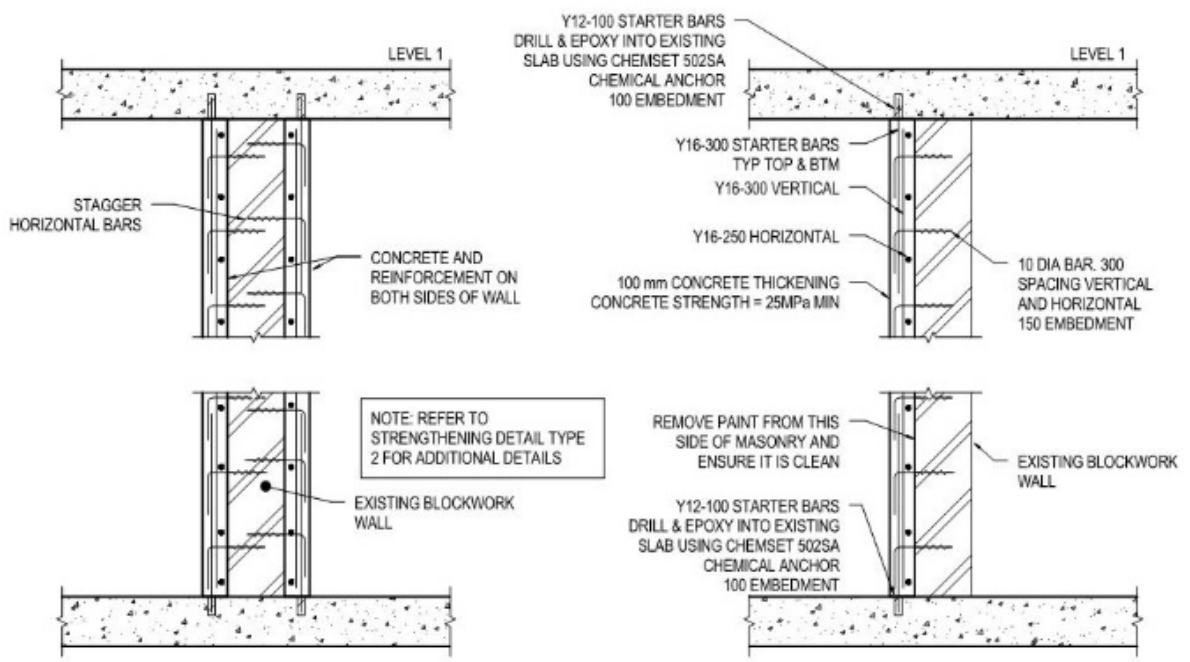

Figure 12: Wall strengthening. 


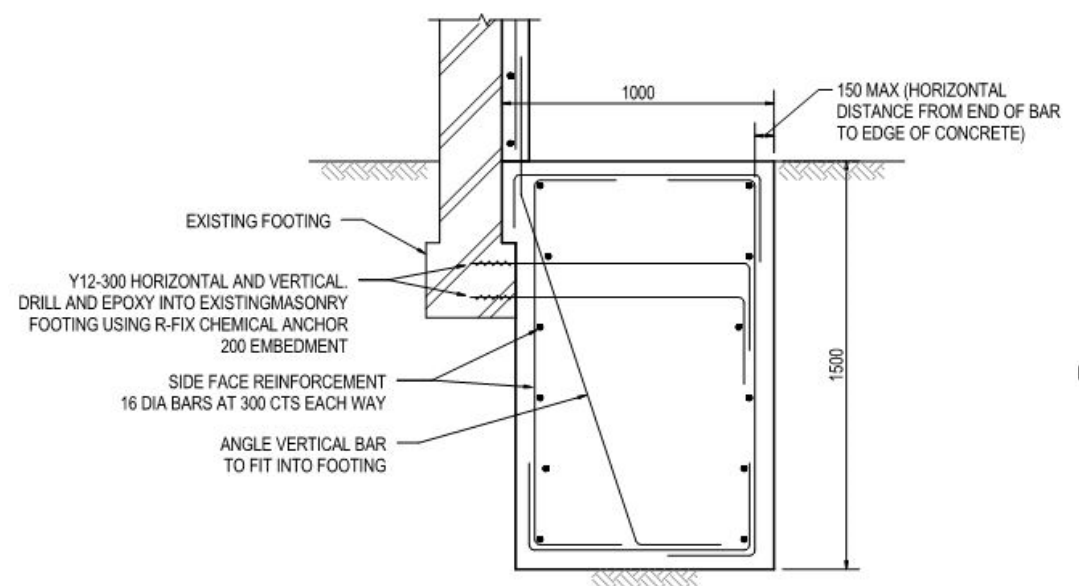

Figure 13: Foundation enlargement.

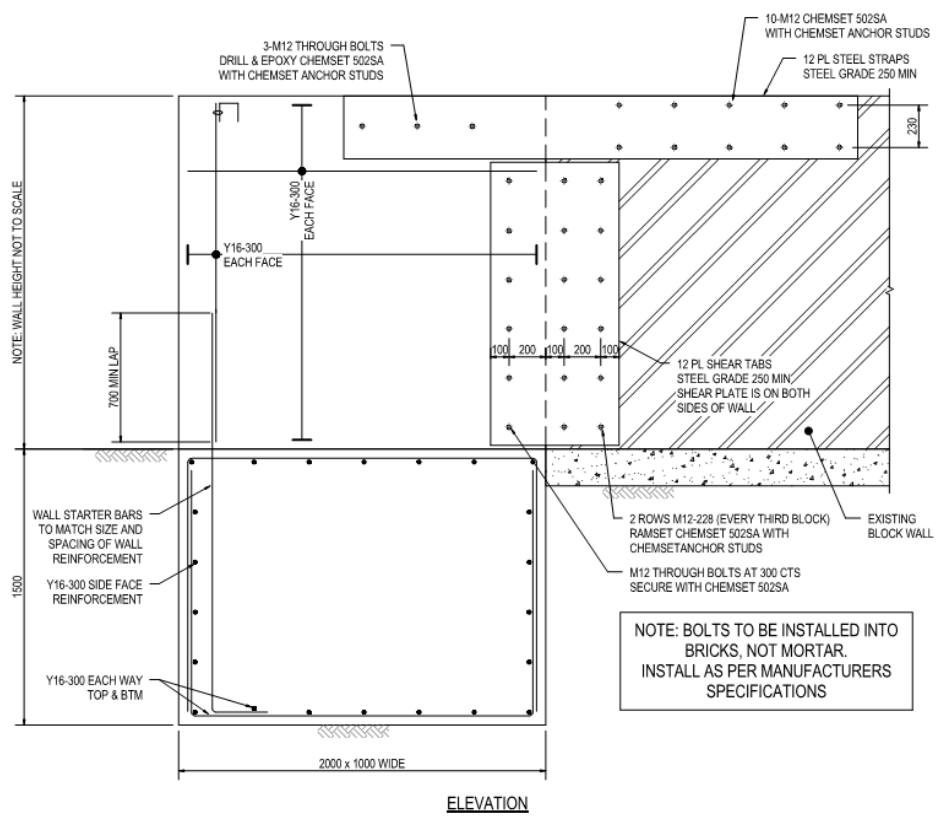

Figure 14: Wall extension.

\subsection{Stitch plates}

The survey team confirmed that there was no continuity of slab reinforcement across building joints. Stitch plates were therefore designed to join the buildings together. Tie forces were read out of the analysis model and stitch plates were designed for in-plane loads. 


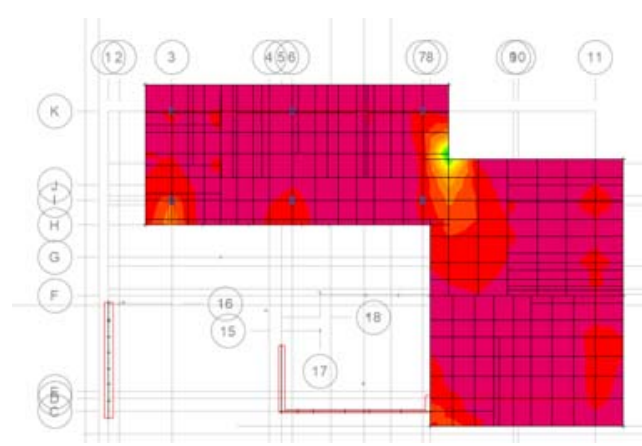

Figure 15: Plan view of in-plane loads in slab.

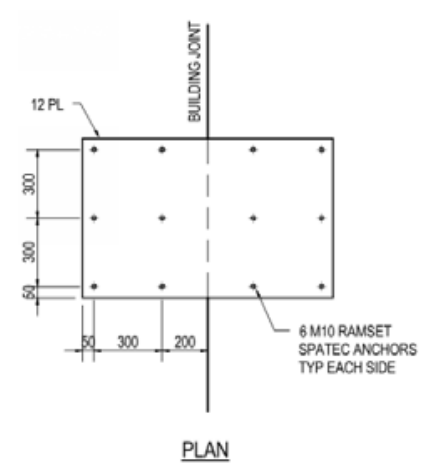

Figure 16: Stitch plate detail.

\section{CONCLUSION}

The aim of this study was to assess the damage that was caused by the 2015 Nepal earthquakes on four buildings in central Kathmandu, to identify structural deficiencies and investigate performance-based requirements for strengthening. The study used ASCE-41 as a general framework for the assessment, but relied on input from numerous codes from around the world to calculate factors where the requirements of ASCE-41 could not be fulfilled due to local constraints. Brick samples were taken from all the buildings, and analysed using American, Indian, Nepalese and Australian building standards to produce material capacity values with a variation of around $10 \%$. The seismic coefficient was also calculated and validated using American and Nepalese codes, with a variation of around $8 \%$. These factors were used in conjunction with site investigations to develop an analysis model in ETABS program which allowed for the identification of areas of excessive stress on the structure and subsequent design of strengthening details.

It was found that wall extension was a very effective way of reducing the amount of strengthening required, particularly within the building footprint. Walls and foundations were typically acceptable in shear and compression, but regularly failed under tension loads, necessitating wall jacketing and foundation enlargement. Stitch plates also had to be installed wherever slab reinforcement was found to be discontinuous across a building joint.

This study may be used by engineers when deciding the best approach to the analysis and design of strengthening of buildings in developing countries.

\section{REFERENCES}

[1] Nepal National Building Code 150, Seismic Design of Buildings in Nepal, Department of Urban Development and Building Construction, 1994.

[2] Nienhuys, S., Seismic Building Codes - Global and Regional Overview, Evidence on Demand, UK Department for International Development, 2015.

[3] American Society of Civil Engineers, Seismic Evaluation and Retrofit of Existing Buildings, (Section 2.3.1), Structural Engineering Institute, 2013.

[4] Kaushik, H.B., Rai, D.C. \& Jain, S.K., Uniaxial Compressive Stress-Strain Model for Clay Brick Masonry. Current Science, 92(4), Feb. 2007. 